\title{
Lexicogrammatical Analysis of Narrative Texts Written by First Semester Students at Unika St. Paulus Ruteng
}

\author{
Maria Olga Jelimun ${ }^{1 *}$, I Wayan Suarnajaya ${ }^{2}$, Ni Luh Putu Sri Adnyani ${ }^{3}$
}

${ }^{1,23}$ English Language Education, Post Graduate Program, Universitas Pendidikan Ganesha, Singaraja

A R T I C L E I N F O

Article history:

Received 29 December

2019

Received in revised

Form 01 January 2020

Accepted 18 January

2020

Available online 28

February 2020

Keywords:

Narrative text transitivity analysis, language use, mood analysis

\section{A B S T R A C T}

This research conducted a qualitative investigation of the transitivity structure, language use and mood structure of narrative texts written by first semester students at UNIKA St. Paulus Ruteng. The data sources of this study were narrative texts written by students on the English study programme. The researchers investigated the dominant transitivity process and analysed the mood structure of the students' narrative texts using Miles and Huberman's interactive model. The researchers collected data from the curriculum documentation and by interviewing and giving exercises to the students. Furthermore, the instrument was the researchers and the students' worksheets. The findings showed that six transitivity processes were applied in the students' writing. The processes were the material process, mental process, verbal process, behavioural process, relational process and existential process. The dominant process used was the material process, since the texts written by the students mostly contained action verbs describing the characters' physical actions. The second most common process was the relational process, which was followed by the mental process with $34.15 \%$. The verbal process accounted for only $7.41 \%$. The other processes contained in the texts were the behavioural process and the existential process, and affect, status and contact were as mood aspect. 


\section{Introduction}

Language is not only about the grammatical structure, but also deals with the social context, which sociologically is seen from the perspective of who speaks to whom, when it happens, and why it happens. This signifies that the study of language is closely related to the social context where the language is used. For instance, the two words hau and ite in Bahasa Manggarai, one of the local languages spoken in the eastern part of Indonesia, have the same meaning of 'you'. The word hau is used when the speaker and the interlocutor are of the same age or have a close relationship. This word is replaced by the word ite when the speaker talks to an older interlocutor. This means that the choice of language is determined by the relationship between the interlocutors. The link between language and its social context was identified in Malinowski's (The Cultural Problem of the Cultural Anthropologist-Hsu-1979-American Anthropologist - Wiley Online Library, n.d.) work based on his study of Trobriand Islanders, in which it is believed that cultural knowledge was needed to understand the social life from the language being used. It should be noted that the link between language and social context has become the concern of systemic functional linguistics (SFL). This indicates that the view of SFL refers to discourse semantics. This means that this branch of linguistic theory has meta-functions that are essential to the way the grammar of language works in the language system. These metafunctions include experiential (ideational), interpersonal and textual meanings. Language features and SFL are a unification that recognises the relationship between language and its social context.

Moreover, the social context in this respect can be categorised into context of culture (genre) and context of situation (register). The importance of language in action arises from the concept of register. Halliday and his friends (1985) developed a more refined structure related to the register concept. They suggest that there are three main categories of register, namely field, tenor and mode. Field relates to the situation that naturally happens or the topic of the situation. Tenor is a register variable that refers to who is talking, the nature of the participants, their status, and the relationship between the participants. Mode is considered as how the language is playing in an interaction in social action. In this part, both interpersonal and experiential meanings are considered as the orientation (Eggins, 1994). The three above-mentioned categories are strictly linked to the language structure. The language structure is divided into three major groups: transitivity, mood and theme structures. To realise the common relationship between the register categories and the clause system, there are three fields of meaning potential for expressing the association between language and context of situation: meaning, interpersonal meaning, and textual meaning. The relationship among the register categories, clause system and meaning potential can be seen in the following table:

Table 1.Register categories, clause system, and meaning potential

\begin{tabular}{lll}
\hline Register Categories & Structure of Language & Meaning Potential (Functional Categories) \\
\hline Field & Transitivity & experiential meaning \\
Tenor & Mood & interpersonal meaning \\
Mode & Theme & textual meaning \\
\hline
\end{tabular}

It can be seen from Table 1 that a language is a form of human beings' activities in a society. Register categories are applied in a language through the structure of language (transitivity, mood and theme). In addition, they have meaning potential, which is perceived through experiential meaning, interpersonal meaning, and textual meaning.

Applicable linguistics as systematic needs an empowering approach (Lukin et al., 2011). SFL was designed to be a holistic theory of language in context, with comprehensive descriptions of the systems of particular languages that could support text analysis and the early descriptions being of lexicon grammar (Halliday, 1964-1978). Dealing with the use of language is also related to genre. Genre is a pivotal concept in English language learning in academic writing. Genre is described through text. In learning language, some types of texts are introduced that involve meaning and aims. They are descriptive text, recount text, report text, analytical, hortatory exposition, and narrative text.

Some previous researchers investigated SFL by studying other types of texts such as descriptive text, recount text, newspaper text, and public speakers' speech. The grammar term appears unpretentious. In our awareness of the importance of grammar in writing text can be realized from the text in terms of linguistics theory (Matthiessen, as cited in Suarnajaya, 2001). Understanding a text cannot only be derived from the knowledge of grammatical and lexical components, but it must also be 
seen from the social context. Signifying the meaning of an expression is based on how it is used. Words used not only denote things, but also denote other functions, such as the relationship between people. In struggling to reminisce SFL, researchers who worked in that field were Firth and Malinowski (as cited in Andrea et al., 2014). They worked to develop this specific linguistics branch. Firth is known as the historian who has alarmed to the use of language. He was concerned with the practical and theoretical aspects of language. Firth explained the language description of its practical aims. He stated that various types of linguistics were defined in terms of syntagmatic and paradigmatic relations, such as grammatical items, lexical items, and phonological items. Over the years, SFL has developed in education though SFL works in discourse analysis. In the educational area, SFL has inspired the language-based research in the context of children's language knowledge in their social relationships. Moreover, SFL occurs not only in oral communication, but also in written communication. In the $21^{\text {st }}$ century, students' literacy is demanded to be balanced either on their speaking, writing or on technology, in which the students should compete to gain their language competency molded with the current demand.

A narrative text is a common text that is learned at school and university. These texts concern legend, fable or even humans' life reflection. Narrative text is recognised as social life's expression and beliefs. Therefore, people use innumerable modes to convey the story depending on to whom the story is told, when it happens, and where it is told. A narrative text is accepted as a part of language. It should also be noted that the importance of a narrative text can be seen from the ideas being expressed in the text and the way that they are expressed. Regarding this, the analysis of the students' narrative texts is categorised as lexicogrammatical. As a type of text, narrative text is included in the Indonesian curriculum (kemendikbud, 2013). It is essential for a teacher to know how the text is composed to deliver the knowledge to the students. A narrative text is the same as other text types, as it not only constructs the text rules regarding its text structure, but also composes the way the text makes meaning. In this case, the students should be taught to see the text based on the SFL context. This means that the students not only correct the sentence structure, but also make the writing relate to the social context of meaning. Halliday states that SFL theory can contribute to writing skill, as it can help the writer to analyse the text contextually. In this context, the teacher should explain to the students the steps in writing, for example, they have to know the topic that they are writing about (ideational meaning), the relationship between the reader and the writer (interpersonal meaning) and the text coherence (e.g. grammar and text reduction) in the context of textual meaning.

The context of language features deals with textual meaning that appears in SFL as register. Register is seen as an element that is used to see the grammar of the text in the context of field, tenor and mood. Different from the previous studies mentioned earlier, this research mainly conducts a lexicogrammatical analysis of narrative texts written by first semester students on the English study programme in UNIKA St. Paulus Ruteng based on SFL theory. The study investigates process types such as the transitivity structure, language use and mood structures of the narrative texts written by the students. This study is expected to assist future researchers to investigate other texts based on SFL. In addition, the English teachers are expected to use this research as guidance to investigate the students' capability in writing narrative text.

Although some previous researchers conducted a similar investigation, the difference is that they investigated SFL through other types of texts, for example, the study conducted by Nurohmah (2013) described in his work entitled An Analysis of Students' Recount Text, by using systemic functional grammar. The similarity between the previous study and the present study is the source of the investigation, as both studies used the students' writing as data. However, these two studies have differences in the concept of the investigation. The previous study explores the linguistics features used in students' writing and the findings show that the students' problem in writing relates to the use of appropriate grammar, such as the use of simple present, simple past, prepositional phrase, and regular and irregular verbs. However, the present study investigates the students' writing in terms of the transitivity and tenor of the text. Moreover, a study conducted by Anggun (2016) investigates the descriptive text in an English textbook in terms of purposes, schematic structure, and linguistics features. The study applied SFL, which was mainly proposed by Halliday. The descriptive text used for this study was from an English textbook for the 2013 curriculum.

Furthermore, Noor, Ali, Muhabat and Kazemian's (2016) work entitled Systemic Functional Linguistics Mood Analysis of the Last Address of the Holy Prophet (PBUH) relates to their study which found that the functional structure based on mood analysis of the text is very useful to understand interpersonal relationships of the participants. The order of the clause elements provides categorisation of the mood of the clauses. This classification also employs certain meaning according to the clause type. The language analysis of religious texts according to SFL mood analysis is a useful 
strategy and requires further investigation with reference to different contexts. Religious texts are the least investigated genre of language. Furthermore, the results of research that was conducted by Alaei and Ahangari (2016) are presented in their work entitled A Study of Ideational Metafunction in Joseph Conrad's "Heart of Darkness": A Critical Discourse Analysis. This study aims to determine how ideology or opinion is expressed in Joseph Conrad's "Heart of Darkness" and what type of lexicogrammatical strategies are used in the first part of this novella to convey the author's ideological meaning. By focusing on the lexicogrammatical choices in the transitivity system of the structure of the clauses, the researcher attempts to shed light on the ideational meaning in the first section of the story, that is, the grammar of the clause as representation (transitivity patterns) of the encoding of experiential meanings, meaning about the world, about experience and about how it is perceived, and experience what is going on. Examining the transitivity patterns in text can explain how the field of situation is being constructed and describe what is being talked about and how shifts are achieved in the field. Both Halliday and Hassan, Matthiessen and Webster (2005) integrated theoretical statements with demonstrations of text analyses.

A similar study was conducted by Li (2015), the results of which are presented in Teaching and Research of Systemic Functional Linguistics in a Regional Context. This research conducts a survey of SFL teaching and research in the Inner Mongolia autonomous region. The investigation found that SFL as a mainstream linguistic theory should be taught not only in the English department of the School of Foreign Languages, but also in other departments such as the Russian and Japanese departments, and even in other schools such as the School of Chinese Studies and the School of Mongolian Studies. Moreover, Manfredi (2016) presents the findings of his research in Systemic Functional Linguistics as a Tool for Translation Teaching: Towards a Meaningful Practice. This research focused on the centrality of meaning in the practice of translation. Since this major concern is shared by SFL (Halliday, 1994; Halliday \& Matthiessen, 2004), which considers language a meaning making resource, it is argued that such an approach could serve as a helpful tool for translator education and training. After a theoretical first part, where the relevance of SFL to the activity of translating is discussed and a cursory sketch of its key notions is outlined, the paper moves on to present illustrative segments from a small selection of English sample texts and of their translation into Italian. Dealing with different text types and drawing on authentic teaching assignments, some lexicogrammatical features are analysed to identify the multidimensional meanings being realised. The specific focus is on modality, ideational grammatical metaphor, thematic progression and appraisal systems, a model for evaluation recently developed within the framework of Hallidayan linguistics (Martin \& White, 2005)

\section{Methods}

This study aimed to investigate the first semester students' narrative texts by using SFL theory. It was conducted by using various methodologies, which are described below.

\section{Research Design}

This study adopted a qualitative research design, as the data was in the form of the students' narrative writing and the researchers analysed the data descriptively by elaborating process types and considering transitivity structure, language use, and mood structure. Moreover, this study aimed to investigate the first semester students' narrative texts by using SFL theory. Narrative text was used in this study as it is as a part of language that is not only considered as a set of rules, but also considered in the context of the social meaning. Therefore, the researchers expected to determine whether the narrative texts written by the first semester students on the English study programme at UNIKA St. Paulus Ruteng had fulfilled the main concept of SFL or not.

\section{Participants}

The participants in this study were the first semester students on the English study programme at UNIKA St. Paulus Ruteng. They were 15 students in class B. The first semester students were chosen as the participants since narrative text was being studied.

\section{Data Collection}

This study is a descriptive qualitative study. The main instruments of this study were the researchers themselves and the students' worksheets. Furthermore, the following procedures were used in collecting the data: a. The researchers conducted a document study on the curriculum implemented in the English study programme at UNIKA St. Paulus Ruteng to determine whether narrative text was introduced to the students or not, $b$. The researchers conducted an interview with 
two of the writing lecturers in the English study programme, and c. The students completed exercises. They were asked to write stories that are familiar to them.

\section{Data Analysis}

This is a descriptive qualitative study as the data is in the form of the students' writing and the researchers explain the data descriptively by elaborating on process types such as transitivity, language use, and mood structures. In analyzing the data, there were some steps that the writers followed, namely data reduction, data display and drawing/verification and conclusion.

a. Data Reduction

Data reduction is associated with the process of selecting, focusing, simplifying, reducing, and organizing the data which have been collected. In this step, through a careful reading of the students' narrative texts, the selected data which were related to the objectives of the study was done through text modification in terms of sentences as well as clauses.

In modifying the texts, the researcher classified each text. In this step, the researcher modified the texts into sentences. The researcher then, investigated the grammatical error did by the students. The next step, the researchers divided the sentences into clauses. The clauses were analized both in terms of transitivity structure as well as mood structure, which are in accordance with systemic functional linguistics theory. The transitivity structure analysis was carried out in order to investigate the grammatical systems such as process types, participants and circumstances, which were used to unload the field of the text. Mood structure analysis of the clauses was investigated as well as the mood elements of the texts. It aimed to help the researcher in organizing and classifying the data.

b. Data Display

The next step after reducing data is data display. It is concerned with presenting an organized, compressed, assembly of information for conclusion drawing. In this step, the writers displayed the data using table. The table was of two types namely transitivity structure table and mood structure table.

c. Conclusion Drawing and Verification

Representating the inferences were the final step after the data were presented. This stage countenance the researcher to move back to contemplate the analyzed data and to assess whether the data findings fited the objectives of the study. At this point, the data which had been examined were re-checked and re-read to develop the conclusions concerning the study. The conclusions, later, were verified continuously.

\section{Result And Discussion}

Three main points are emphasised in this study. It investigates process types such as the transitivity structure, language use and mood structure of narrative texts written by the first semester students on the English study programme at UNIKA St. Paulus Ruteng. To investigate the transitivity structure, 15 texts were used as the data for this research. It was found that all the texts studied have various degrees of each process, as shown in Table 2.

Table 2. Process types

\begin{tabular}{lccccccc}
\hline & & \multicolumn{3}{c}{ Process Types } & \multicolumn{2}{c}{ Relational } \\
Students' code & Material & Mental & $\begin{array}{c}\text { Behaviora } \\
\mathbf{1}\end{array}$ & Verbal & $\begin{array}{c}\text { Existentia } \\
\text { l }\end{array}$ & $\begin{array}{c}\text { Attributiv } \\
\text { e Identifyin }\end{array}$ & $\mathbf{g}$ \\
\hline CO(text 1) =36 & $21(58,33 \%)$ & $7(19,44 \%)$ & 0 & $1(2,77 \%)$ & $1(2,77 \%)$ & $6(6,16 \%)$ & 0 \\
AT (text2)=44 & $27(61,36 \%)$ & $6(13,63)$ & $2(4,54 \%)$ & $1(2,27 \%)$ & $2(4,54 \%)$ & $5(11,36 \%)$ & 0 \\
JR(text3)=26 & $14(53,85)$ & $2(7,69)$ & 0 & $1(3,85 \%)$ & $1(3,85 \%)$ & $8(30,77 \%)$ & 0 \\
HS(text4)=23 & $12(52,17 \%)$ & $2(8,69)$ & $1(4,34 \%)$ & $2(8,69 \%)$ & $\mathbf{0}$ & $6(26,8 \%)$ & 0 \\
MS(text5)=30 & $21(70 \%)$ & $4(13,33 \%)$ & $\mathbf{0}$ & $3(10 \%)$ & $\mathbf{0}$ & $2(6,66 \%)$ & 0 \\
NJ(text6)=44 & $27(61,36 \%)$ & $5(11,36 \%)$ & $1(2,27)$ & $5(11,36)$ & $\mathbf{0}$ & $6(13,63 \%)$ & 0 \\
KH(text7)=33 & $25(75,76)$ & $2(6,06 \%)$ & $\mathbf{0}$ & $1(3,03)$ & $\mathbf{0}$ & $5(15,15 \%)$ & 0 \\
HH(text8)=35 & $16(45,71 \%)$ & $14(40 \%)$ & $1(2,85 \%)$ & $2(5,71 \%)$ & $\mathbf{0}$ & $2(5,71 \%)$ & 0 \\
HF(text9)=32 & $16(50 \%)$ & $5(15,62 \%)$ & $4(12,5 \%)$ & $2(6,25 \%)$ & $1(3,12 \%)$ & $4(12,5 \%)$ & 0 \\
IJ(text10)=30 & $17(56,67) \%$ & $4(13,33 \%)$ & $\mathbf{0}$ & $2(6,66)$ & $1(3,33)$ & $6(20 \%)$ & 0 \\
& & & & & & & \\
\hline
\end{tabular}




\begin{tabular}{lccccccc}
\hline PF(text11)=38 & $24(63,15)$ & $5(13,15 \%)$ & $\mathbf{0}$ & $5(13,15 \%$ & $1(2,63 \%)$ & $1(2,63 \%)$ & 0 \\
VJ(text12)=48 & $24(50 \%)$ & $10(20,83 \%$ & $2(4,16 \%)$ & $2(4,16 \%)$ & $1(2,08 \%)$ & $9(18,75 \%)$ & 0 \\
VMO(text13)=5 & $33(57,89 \%)$ & $7(12,28 \%)$ & $\mathbf{0}$ & $6(10,52 \%$ & $\mathbf{0}$ & $11(19,29 \%$ & 0 \\
$\mathbf{7}$ & & & & & \\
MS(text14)=34 & $15(44,11 \%)$ & $5(14,70 \% 0$ & $1(2,94 \%)$ & $6((17,65$ & $1(2,94 \%)$ & $6(17,65)$ & 0 \\
VHJ(text 15)=40 & $16(40 \%)$ & $7(17,5 \%)$ & $1(2,5 \%)$ & $4(10 \% 0$ & $2(5 \%)$ & $10(25)$ & 0 \\
\hline
\end{tabular}

Table 2 shows that the material process is the most common process used by the students. It shows the similarities between one student and other students in constructing the story. The second most common process used in the 15 narrative texts written by the students is the relational process. Based on the analysis of all the narrative texts studied, $36.38 \%$ of the texts used the relational process. All the narrative texts written by the students included the relational process. The use of the process in all the texts was mostly applied to describe the personality, job and names of the characters in the story. Those cases have been applied in nominal sentences. Moreover, the mental process is in third position. All the narrative texts written by the students included the mental process. The analysis shows that in the 15 narrative texts, $34.15 \%$ include the mental process. The process is used as the writer tends to show the readers the feelings, thoughts and the sense action of the characters in the story. This is shown through the use of the words 'listen', 'hear', 'feel' and 'thought'. This process is followed by the verbal process. This process is used in around $7.41 \%$ of all 15 narrative texts written by the students and all the students used the verbal process in their texts. The verbal process was shown through the use of verbal words in constructing the texts, such as the use of 'tell' and 'say'. The other processes are the behavioural process and the existential process. It was found that these two processes are used in the smallest proportion of all the narrative texts in the study. The behavioural process accounts for around $5.42 \%$ of all the narrative texts; however, some texts, i.e. text 1, text 3 , text 5 , text 10 , text 11 and text 13 , do not contain the behavioural process. The behavioural process is used less in the texts, as most of the students described the characters' behaviour through physical action words. Another process that is used less is the existential process. This process accounted for $4.54 \%$ of all 15 narrative texts in this study. Some narrative texts, i.e. text 4 , text 5 , text 6 , text 6 , text 7 , text 8 and text 13, do not use this process. The existential process is used the least, as the texts written by the students have only few parts showing the existential aspect of the characters of the story and the use of the word 'there' is rarely used in all the texts.

Furthermore, regarding the language use in narrative texts written by the first semester students, the researchers investigated the language processes used through affect and status, in which the register category is seen as tenor. Affect is seen as the formulation of the attitude of the participants in the text. This can be through positive polarity or negative polarity. Each of the 15 texts grants is mostly in negative polarities. There are only a small number of clauses in each of the texts showing affect through positive polarity. This happens as the content of all the narrative texts written by the students describes a sad freak in the story. To illustrate the use of negative polarity in the texts, the number of the clauses in the texts is different. There are 15 affects showing the sad freak of the texts. The negative polarity that has been shown in those clauses mostly relates to the action done by the characters 'stepmother' and 'step-sister' of Cinderella in the story. This can be seen in the following examples:

a. In the clause 'she was so sad', the word 'sad' has a negative meaning here because it shows the feeling that causes the human to be upset. In the clause 'her stepmother and sister being cruel to her', the use of the word 'cruel' has a negative perspective in real life, in which someone makes other people's lives uncomfortable.

b. In the clause 'her stepsister and sister treat Ella like a housemaid', the words 'like a housemaid' show a negative meaning, as the profession of being a housemaid is recognised as a low profession in the society.

c. In the clauses 'she doesn't forget' and 'but her stepmother didn't allow her', the negative polarity is shown through the words 'doesn't' and 'didn't'.

d. In the clauses 'she can't do anything' and 'they didn't recognize her', the negative polarity is shown through the words 'can't' and 'didn't'.

There are ten cases of negative polarity showing the affect aspect in another text. Those cases can be seen in the following clauses: 
a. In the clause 'but her stepmother and sister don't like her', the two words representing the negative polarity in the clause are 'but' and 'don't'.

b. In the clauses 'they always tortured her' and 'and all the homework she always work alone', the negative polarity is shown through the words 'tortured' and 'alone', as these two words have a negative perspective.

c. In the clauses 'her father didn't know it' and 'they tortured her carelessly', the negative polarity is shown through the words 'didn't', 'tortured' and 'carelessly'.

d. In the clauses 'her stepmother and sister prohibit her' and 'Cinderella was sad', the negative polarity is presented in the words 'prohibit' and 'sad'. In the clause 'she cried her self and laminating herself' the words 'cried' and 'laminating' are recognised as negative polarity.

The other texts have some other clauses showing the negative polarity, with each clause having different ways to present the affect, such as in the following clauses:

a. In the clauses 'because the salary is low' and 'he was sad', the words 'low' and 'sad' lexically have negative meaning.

b. In the clauses 'his mom was so sad' and 'his mom felt so sad', the word 'sad' shows a negative meaning.

c. In the clauses 'her son changed' and 'she was angry', the negative polarity is shown by the words 'changed' and 'angry'. Although the meaning of the word 'changed' in real life has two sides (negative and positive), in the context of this text, the word 'changed' is on the negative side.

d. In the clause 'she curse him into stone', the negative polarity has been shown by the word 'curse'.

Regarding status, the study investigates the scale of the equal and unequal reciprocity between the writer and his/her addressee. This is seen through the use of informal lexical items, the use of personal names, and the use of interpersonal metaphor. The students' texts prove that regarding the status of all the texts in the study, the researcher investigates it through the language use in the texts. Almost all of the 15 narrative texts written by the students used informal lexical items. They are categorised as informal lexical items as the students constructed the story in informal language. As informal language, all the students write the story using daily communication words. This case may have occurred because of the considerations of the readers' story. Moreover, the use of informal lexical items in the narrative texts in the story about Cinderella may be due to the consideration of the relationship between the characters. These two texts have four main characters (stepmother, stepsisters, Cinderella and fairy godmother) and the characters of the story do not indicate the lower and higher level of status but just the relationship between children and mother or family terms. In addition, in the story about Malin Kundang, the text just describes the relationship between a son and his mother and there is no idiosyncrasy.

Furthermore, the mood structure analysis of the narrative texts written by the first semester students investigated how the students' texts were constructed. It was determined with the vocabulary choice and tenses used in the texts that show the interpersonal meaning. The students' texts showed that the first semester students lack capability in constructing the ideas of narrative texts. The students have constructed the texts mostly using common verbs. They do not have the capability to convey the content of the story. This can be proved in the way they wrote the narrative texts in this study. Almost all the writers of the narrative texts constructed the story monotonously, where they just conveyed the ideas of the texts through common verbs such as 'is', 'are', 'was', 'do', 'does', 'did' and 'have/has' to show the interpersonal relationship of each of the characters in the story. There were only few cases of mood with modal auxiliary and mood adjunct in the texts to soften the utterance, such as in the clauses 'and his mom was always sick', 'and she always work hard', 'he never back again', and 'in several years Malin never back again'. The mood adjunct in these clauses is shown through the words 'never' and 'always'. Moreover, indirectly in writing the texts, the students did not avoid making grammatical errors. This reminds us that the students who were the participants in this study were not English native speakers.

In this section, there are some elements that the researcher investigated. They are the use of the 'to' with an infinitive, quantifiers, sentence pattern, article, and plural. Regarding the use of 'to' with an infinitive, the students are mostly confused, as the they thought that every past event must use a past tense verb in constructing the sentence without understanding the exception of their use. This can be seen in the following data:

After mourn time, her father wanted to married again.

He is a naughty boy. When he is adult he told to his mom to went to the city.

One day Malin Kundang wanted to became a successful person then he went away from his house although his mom disagreed with his decision. 
The data above shows that the students do not understand how to use 'to' with an infinitive in English. They do not have enough knowledge of the exchange of words in English, as in Indonesian there is no regulation of exchanging words either in an infinitive or in the use of 'to' with an infinitive. Therefore, this generalisation seems to be a convention for the students in constructing the text. Furthermore, errors are made by the students in the tenses of the verbs. Narrative texts use the past tense in their construction, but some students were confused about that. This case can be seen in the following examples:

She come to him but Malin ignore her and saying.

His whole body turn into stone.

His mother don't allow him to went to the city but he construct to went.

The data above proves that the students are not familiar with the change of tenses. In addition, the students lack knowledge of the basic tenses that must be used in describing or narrating a past event. This situation occurred because of their mother tongue (Bahasa Manggarai). As an Indonesian speaker, the author realised that no tenses are introduced in Indonesia. The Indonesian speakers are not familiar with the word change when the tense changes. Furthermore, the article was a problem for the students in constructing their narrative texts. The article is placed before a noun or to modify a noun. However, in constructing the narrative texts, the students in this study placed the article incorrectly. This can be seen in the following examples:

Once upon a time, in the village lives the widow and the son.

He is the arrogant.

Malin Kundang lived a happily.

The mistakes above are also influenced by the use of Bahasa Manggarai, in which an article is not used either orally or textually. In addition, there are errors in the use of the plural form. The plural form is recognised as denoting that there is more than one. The plural form is commonly introduced through the use of the suffix 's' added to the noun. There is incorrect use of the plural form in the narrative texts written by the students in this study. These errors can be seen in the following data:

There a poor womans \& her son exactly in west Sumatra her son named Malin Kundang.

Instantly, Malin Kundang \& his wife become a stones.

Everyday he caught fishes in the sea and he brought it to his mother.

The data above shows that the students do not have an adequate understanding of adding the suffix ' $s$ ' to represent the plural form. In addition, the students expected that to show the plural form, the suffix 's' must be added even though there are some irregular plural forms in English. It can be concluded that the students made these mistakes as they did not know how to use the correct plural form. Moreover, in Bahasa Manggarai, the suffix 's' representing the plural form is not used.

The findings of this research analysing students' texts from the SFL perspective show that the first semester students on the English study programme at UNIKA St. Paulus Ruteng faced many problems in adjusting the social function of the text. Furthermore, the students were not creative in constructing the stories. This has been proved in how their narrative texts are written, as they wrote the texts predominantly using the material process to construct the story by focusing on the action done by the characters of the story. Moreover, in expressing other sides of the story, such as the interpersonal meaning of the story, it is evident that the students lack capability in choosing the vocabulary, as most of the content of the 15 texts studied is monotonous as the vocabulary used in constructing the ideas is mostly the same. This happened as the students have a lack of vocabulary, are not familiar with the formal words, and do not have adequate creativity in expressing ideas. The language processes used in expressing the ideas of the students are mostly in common vocabulary, in which most of the writing has used the daily words.

The results of this study are consistent with the results obtained by previous researchers such as Nurohmah (2013), which show that the students find it difficult to express their ideas as they do not manage aspects regarding refer- ring expressions. It is difficult for them to identify cataphoric, anaphoric and exophoric expressions in texts. Students are not accustomed to identifying words, especially pronouns that refer to words given earlier or later in a passage and they are not good at following the development of ideas in the texts.

Moreover, the impact of the mood aspect is diminished in the narrative texts in this study. This is proved by the findings, which show that in conveying the ideas, most of the students mainly used common verbs such as 'is' 'are', 'do', 'does', 'did', 'have' and 'has'. This finding is supported by Zhang (2017), who found in his study that most of the participants clarified the ideas mainly with common 
phrases such as 'be+noun'. This happened as the relationship between the writer and the readers is considered to be on the same level.

Furthermore, the results of this current study align with the results of a study that was conducted by Anggun (2017), which shows that regarding the SFL in descriptive texts written by the students, the linguistic features used in the texts are mostly the material process since the students predominantly used action words.

However, the results of this study are not consistent with the results of a study that was conducted by Tshotsho (2014), which show that the students' preparation for writing the texts is more sophisticated as it relates to the implementation of SFL, and therefore the students' texts have more value in grammatical features, language resources and the interpersonal meaning.

Another contrasting result was found by Briones (2016), whose research findings showed that the students' writing can be used to show the relationship between writer and readers in the case of approval, disapproval, acceptance, rejection, certainty and uncertainty. This was caused by the predominant use of mood and modality. The use of those elements makes the readers understand the point of the text clearly. Conversely, in this current study, the use of modality is decreased.

Furthermore, the contrasting result is supported by the result of a study that was conducted by Emilia (2015), which shows that the SFL in the students' writing was implemented well even though there were still some students who made a few mistakes in the grammatical aspect.

Based on the discussion above, it can be concluded that the quality of SFL in the students' writing is not equal. Most of the students wrote a text without paying attention to the contextual meaning. In addition, the students' capability in playing with the words in constructing the texts is moderate. This can be proved by the vocabulary that they chose when writing the texts. Almost all the texts used the common words and there was no significant diversity in each of the texts written

\section{Conclussion}

The basic nature of the language of the first semester students at UNIKA St. Paulus Ruteng and the social context of the language they used in their narrative writing and they consciously produced through the framework that acceptable in social life. To investigate the linguistic structure of students' narrative texts, SFL was applied in this study. Due to time constraints, only certain aspects were selected for the analysis. A decision was made to analyse the nominated texts in terms of the register categories of field and tenor. In addition, the researcher investigated the application of the mood aspect in the 15 narrative texts written by the first semester students on the English study programme at UNIKA St. Paulus Ruteng. The texts are used to determine the relationship between the language speakers, used in the texts with the social context, as encouraged by the initiators of SFL. The supporters of this theory suggested that all the language that someone uses in writing his/her narrative text is related to the social context. Regarding the transitivity analysis, all the texts studied incorporate the use of material, mental, verbal, relational and existential processes. The material process was used the most in the texts. It was followed by the mental process, the relational process and the verbal process. The smallest part was represented by the existential process.

Regarding the language process analysis of the study, it essentially aimed to expose the social relationship between the participants involved in the texts. The texts are analysed using several aspects, namely affect, status, contact and mood structure. In investigating the affect of the narrative texts, it was found that this is mostly presented through positive polarity and some negative polarity. Due to the use of negative polarity, the writers of the 15 narrative texts do not totally show through negative sentences such as the use of the verbs isn't, doesn't, didn't, etc., but some negative polarity is shown through the words that have negative meaning, such as the use of the words 'sad (not happy), force, poor, hard, etc. The 15 texts that have been analysed mostly used informal lexical items, in which the students who wrote the texts had commonly used informal language in curving the content of the texts. Furthermore, in the case of personal names, the writers used only a few personal names in the texts and the names were used just to introduce the characters of the story.

Furthermore, due to the mood structure, the writers of the 15 narrative texts in this study have written the texts mostly in the common mood aspect with the use of common verbs such as is, are, do, does, did, have and has. Even though some texts used modal auxiliaries and mood adjunct in showing the variations of the texts, they were few in number. Moreover, this study proved that the use of SFL is appropriate when it is used to analyse language in students' writing. 


\section{Reference}

Alaei, M., \& Ahangari, S. (2016). A Study of Ideational Metafunction in Joseph Conrad 's " Heart of Darkness ": A Critical Discourse Analysis. 9(4), 203-213. https://doi.org/10.5539/elt.v9n4p203

Andrea, P., Montes, G., María, A., Barboza, S., Isabel, A., \& Olascoaga, L. (2014). Systemic Functional Linguistics and Discourse Analysis as Alternatives When Dealing With Texts. 16(2), 101-116.

Anggun, S. K. (2016). AN ANALYSIS OF DESCRIPTIVE TEXT IN ENGLISH TEXTBOOK USING TRANSITIVITY SYSTEM ( A CASE STUDY OF READING PASSAGES ). 4(1), 147-158.

Ansary, H. (n.d.). The Generic Integrity of Newspaper Editorials : A Systemic Functional Perspective.

Briones, R. R. Y. (2016). Textual Analysis through Systemic Functional Linguistics. Journal of English Language Teaching and Linguistics, 1(2). https://doi.org/10.21462/jeltl.v1i2.27

Emilia, E., \& Hamied, F. A. (2015). Systemic Functional Linguistic Genre Pedagogy (Sfl Gp) in a Tertiary Efl Writing Context in Indonesia. TEFLIN Journal - A Publication on the Teaching and Learning of English, 26(2), 155. https://doi.org/10.15639/teflinjournal.v26i2/155-182

Ettaleb, M., Latiri, C., Douar, B., \& Bellot, P. (2016). SBS 2016 track mining: Classification with linguistic features for book search requests classification. CEUR Workshop Proceedings, 1609, 1079-1088.

Grammar, F., \& Grammar, F. (n.d.). Halliday 's Introduction to Functional Grammar.

Lapoto, S., \& Potradinata, A. (2018). An Analysis of Student' s Descriptive Text Writing in Systemic Functional Linguistic ( SFL ) Perspectives. $4(2)$. https://doi.org/10.18178/ijlll.2018.4.2.161

Li, M. (2015). Teaching and Research of Systemic Functional Linguistics in a Regional Context. 8(5), 189-194. https://doi.org/10.5539/elt.v8n5p189

Lukin, A., Moore, A., Herke, M., Wegener, R., \& Wu, C. (2011). Halliday's model of register revisited and explored. Linguistics and the Human Sciences, 4(2), 187-213. https://doi.org/10.1558/lhs.v4i2.187

Manfredi, M. (n.d.). Systemic Functional Linguistics as a tool for translation teaching: towards a meaningful practice. 49-62.

Noor, M., Ali, M., Muhabat, F., \& Kazemian, B. (2016). Systemic Functional Linguistics Mood Analysis of the Last Address of the Holy Prophet ( PBUH ). 4, 1-9. https://doi.org/10.11648/j.ijll.s.2016040101.11

Nurohmah, I. (n.d.). An Analysis of Students ' Recount Text by Using Systemic Functional Grammar. 1(2), 89-98.

The Cultural Problem of the Cultural Anthropologist - Hsu - 1979 - American Anthropologist - Wiley Online Library. (n.d.).

Tshotsho, B. (2014). Assessing Students ' Academic Writing Using Systemic Functional Linguistics at a University in South Africa. 6(3), 425-433.

Wei, J. (2014). Theme and thematic progression in learner English: A literature review. Colombian Applied Linguistics Journal, Vol. https://doi.org/10.14483/udistrital.jour.calj.2014.1.a06

Zhang, J. I. E. (2017). A Comparative Study of English Systemic Functional Linguistics in the Conclusion of the Thesis. (Adess), 87-92. 